\title{
Os sistemas educacionais no contexto da transição da Nova Gestão Pública para a Pós-Nova Gestão Pública: estudo comparado entre Brasil e Espanha ${ }^{1}$
}

\section{Educational systems in the context of the transition from New Public Management to the Post-New Public Management: comparative study between Brazil and Spain}

\author{
Juliano Mota Parente* \\ Lourdes Belén Espejo Villar**
}

\begin{abstract}
RESUMO
O objetivo do presente artigo é sistematizar a transição da Nova Gestão Pública (NGP) para a Pós-Nova Gestão Pública (PNGP), verificando em que medida estes modelos influenciaram na atualidade os sistemas educacionais do Brasil e da Espanha. A partir das reformas na administração pública e na gestão educacional ocorridas após a década de 1990, podemos observar a implementação de políticas públicas embasadas na NGP e na PNGP, fortalecendo o discurso do institucionalismo mundial e das ideologias globais que defendem um Estado supranacional e regulador de um sistema educacional padronizado. Neste contexto, o nosso objeto de estudo se concentra na educação pública no Brasil e na Espanha,
\end{abstract}

1 Apresenta resultados parciais da pesquisa de Pós-Doutorado no Exterior (Universidad de Salamanca) financiada pela Coordenação de Aperfeiçoamento de Pessoal de Nivel Superior (CAPES).

*Universidade Estadual Paulista. Marília, São Paulo, Brasil. E-mail: julianomparente@ gmail.com - https://orcid.org/0000-0001-6309-9632

** Universidad de Salamanca. Salamanca, Espanha. E-mail: 1bev@usal.es - https://orcid. org/0000-0003-3066-6228 
analisando as interferências no campo da política e da gestão educacional. Metodologicamente, o trabalho se construiu a partir de uma perspectiva comparada dos sistemas educacionais do Brasil e da Espanha, seguindo o enfoque formal (PEGORARO, 2010) e a teoria da economia internacional (COHEN, 2008). Os dados analisados nos permitiram referenciar a influência da NGP e da PNGP nos sistemas educacionais dos países estudados, legitimando uma tendência de racionalidade educacional global.

Palavras-chave: Educação. Pós-Nova Gestão Pública. Sistemas educativos. Gestão educacional.

\begin{abstract}
The purpose of this article is to systematize the transition from New Public Management (NGP) to Post-New Public Management (PNGP), verifying the extent to which these models have currently influenced the educational systems of Brazil and Spain. From the reforms in public administration and educational management that took place after the 1990s, we can observe the implementation of public policies based on NGP and PNGP, strengthening the discourse of world institutionalism and global ideologies that defend a supranational and regulatory state of a standardized educational system. In this context, our object of study focuses on public education in Brazil and Spain, analyzing the interferences in the field of educational policy and management. Methodologically, the work was built upon a comparative perspective of the educational systems of Brazil and Spain, following the formal approach (PEGORARO, 2010) and the theory of international economics (COHEN, 2008). The analyzed data allowed us to refer to the influence of NGP and PNGP in the educational systems of the countries studied, legitimizing a trend of global educational rationality.
\end{abstract}

Keywords: Education. Post-New Public Management. Educational systems. Educational management.

\title{
Introdução
}

As Reformas na Administração Pública ocorridas na década de 1990 desencadearam modelos de gestão educacional embasados na Nova Gestão Pública (NGP) e, posteriormente, na Pós-Nova Gestão Pública (PNGP), em vários países do mundo. Influenciadas por essas tendências globalizadoras, os sistemas educacionais foram adaptando-se a uma nova realidade, legitimando 
uma "agenda global estruturada para a educação" (DALE, 2004, p. 426), convergindo as diretrizes e as legislações educacionais em diversos países para modelos educacionais padronizados.

A NGP surge como uma estratégia de renovação do setor público promovida por meio de reformas que englobavam a desregulamentação, descentralização e flexibilização organizacional (MOLLER; SKEDSMO, 2015). As políticas públicas educacionais implementadas a partir da NGP objetivaram a redução do gasto público e da estrutura burocrática, estimulando a competitividade e a mercantilização dos serviços públicos. Apesar de haver um relativo consenso nas diretrizes da NGP implementada em vários países do mundo, resultando na consolidação de novas maneiras de pensar a administração pública, outros autores, como Oliveira (2015), consideram que a NGP não é homogênea.

No que se refere à PNGP, a literatura destaca que a sua relação com a NGP ainda não é suficientemente clara, tendo em vista a divergência de opiniões que não explicitam se houve uma ruptura ou uma continuidade doutrinal (GYÖRGY; ROSTA, 2015). Alguns pesquisadores informam que ainda faltam elementos capazes de mostrar que a PNGP surge como uma reação à NGP, desconstruindo as reformas por ela implementadas.

Diante deste contexto evidenciado por diversos autores (PUELLES, 2009; SUBIRATS, 2001; HOOD, 2000), formulamos a seguinte questão de pesquisa: quais as principais influências dos novos modelos de gestão (NGP e PNGP) nos sistemas educacionais de Brasil e Espanha? O objetivo do presente artigo é sistematizar a transição da NGP para a PNGP, verificando em que medida estes modelos influenciaram na atualidade os sistemas educacionais do Brasil e da Espanha.

$\mathrm{O}$ argumento que fundamenta nosso trabalho é o transnacionalismo (LINGARD; RAWOLLE, 2014). Um fenômeno que contribui para a construção de uma política global e para a consolidação de "modelos universais de educação, de estado e de sociedade" (DALE, 2004, p. 425) que, estimulado por organismos internacionais $(\mathrm{BM} \mathrm{e} \mathrm{OCDE})^{2}$, fortalecem discursos e práticas convergentes no âmbito do "institucionalismo mundial". Diante destas premissas se defende a lógica de um Estado supranacional, em sintonia com as ideologias globais do ocidente (DALE, 2004), que privilegiam as estruturas formais da sociedade capitalista enfatizando a racionalidade, o progresso, o individualismo e a justiça como pressupostos de uma cultura universalística dominante.

2 Banco Mundial e Organização para a Cooperação e Desenvolvimento Econômico, respectivamente. 
A metodologia da nossa pesquisa se estabelece a partir das bases teóricas do direito comparado (PEGORARO, 2010), buscando na legislação educacional os elementos formais que nos auxiliaram na elaboração das categorias de análise. Concomitantemente, fundamentamo-nos na teoria econômica internacional (COHEN, 2008), que trata de determinar possíveis confluências de dinâmicas entre sistemas políticos divergentes, relacionados a aspectos sociais, culturais e geográficos, concernentes a transferências políticas realizadas pelos governos (STEINER-KHAMSI, 2015).

A partir desses pressupostos, nossa investigação possibilitou conhecer melhor a educação pública nos dois países, objeto de estudo da pesquisa, identificando alguns elementos que nos auxiliam na compreensão dos sistemas educacionais brasileiro e espanhol.

Diante dessas premissas, nossa opção metodológica foi o método comparado entre Brasil e Espanha. Utilizados de forma ampla entre os pesquisadores, os estudos comparados de sistemas educacionais permitem identificar elementos convergentes, diante de realidades distintas, que configuram uma tendência de mecanismos e procedimentos de gestão globalizados. A escolha dos países ocorreu em função de uma estrutura político-administrativa similar, embora com diferenças marcantes que apontam para as especificidades de cada um deles. O Brasil é uma federação dividida em 26 estados e 1 Distrito Federal e situa-se geograficamente na América Latina, compondo um bloco de países do Mercosul $^{3}$. A Espanha é uma monarquia parlamentarista dividida em 17 Comunidades Autônomas e 2 cidades autônomas e faz parte da União Europeia ${ }^{4}$. Tanto Brasil como Espanha têm implementado políticas de descentralização educacional com regulação do governo central, sendo que ambos ampliaram as relações institucionais com o setor privado no âmbito da educação.

$\mathrm{O}$ artigo está estruturado da seguinte forma: na primeira parte apresentaremos os principais aspectos relacionados à transformação da NGP para a PNGP, sistematizando os princípios que regulam as duas tendências, bem como os argumentos que as fundamentam. Na segunda parte descreveremos as principais influências da NGP e da PNGP nos sistemas educacionais do Brasil e da Espanha a partir das categorias de análise. 


\section{A expansão da NGPe sua transição para a PNGP no contexto educacional}

O final do século XX foi marcado por uma série de transformações políticas e econômicas na administração pública, oriundas das reformas implementadas em diversos países, principalmente na Europa e nas Américas. Para alguns autores, essas mudanças foram embasadas nas estratégias da Nova Gestão Pública, concretizadas como um novo paradigma do setor público (VAN GESTEL; TEELKEN, 2004).

Neste sentido, a NGP é entendida como um modelo de gestão que se fundamenta na administração empresarial e que tem por objetivo modernizar a administração pública a partir de mecanismos de eficiência e qualidade, atualizando e corrigindo as limitações da burocracia tradicional (HOOD, 2000).

Em termos institucionais, a NGP "mantiene las ideas de la administración central que consideran como aspectos clave la dirección, la administración y el control" (VAN GESTEL; TEELKEN, 2004, p. 437), ou seja, corroborando a lógica transnacional, o Estado descentraliza os "serviços públicos" por meio de concessões e parcerias públicas, mas continua como regulador dos serviços (BALL, 2014).

Com relação à influência da NGP nos sistemas educacionais, Maroy e Voisin (2013) destacam que cada vez mais o "Estado avaliador" estabelece diretrizes no sentido de criar mecanismos de direção e controle (indicadores) que possibilitem um monitoramento das escolas e dos órgãos de gestão a elas relacionados em nível intermediário. Os mesmos autores esclarecem que há quatro dimensões que consolidam políticas regulatórias nos sistemas educacionais: a escola concebida como um sistema de produção, a ênfase no conhecimento quantitativo, a centralidade nos instrumentos de avaliação e desempenho e a implantação de ferramentas de ação pública de prestação de contas (accountability).

Ainda no contexto das Reformas na administração pública, já adentrando no século XXI, observa-se um período de efervescência política e econômica, que abre espaço para o surgimento de novas propostas e discursos que ocupam centralidade nas agendas públicas. Menos ortodoxas que a NGP, novos conceitos passam a ser utilizados com frequência, tais como Terceira Via, comunidades em redes e administração conjunta, ensejando políticas públicas mais flexíveis e menos normativas. Essas concepções marcam uma nova tendência na administração pública e que passou a ser chamada de Pós-Nova Gestão Pública (PNGP). Não há um consenso entre os pesquisadores que investigam a transição da NGP para a PNGP, nem mesmo no que se refere ao espaço temporal de cada uma delas. Alguns autores defendem que a NGP corresponde "[...] a un lapso que comprende las décadas de 1980-1990, mientras que la PNGP es 
más contemporánea y nace durante la segunda mitad de la década de los años 2000" (VÉLEZ; ORTIZ, 2016, p. 107). Há divergências também com relação à abrangência das duas vertentes, ou seja, até que ponto a PNGP traz alguma contribuição nova, ou é apenas uma reformulação da NGP?

Existem também divergências entre teóricos da área da administração pública no que se refere à nomenclatura. Alguns pesquisadores consideram a Nova Gestão Pública e a Nova Governança Pública como sinônimos (HOOD, 2000), compreendendo que a governança surge como elemento de continuidade das características e princípios da NGP. Outros autores utilizam o termo Nova Governança Pública para designar o movimento de mudanças preconizado pela PNGP (OSBORNE, 2006). Nesse caso, o termo "governança", como elemento novo, justifica a configuração da PNGP.

Neste artigo, consideramos as concepções de autores que fazem uma comparação entre as duas correntes (NGP e PNGP), refletindo acerca de suas diferenças e semelhanças (VAN GESTEL; TEELKEN, 2004; VÉLEZ; ORTIZ, 2016).

Segundo Vélez e Ortiz (2016, p. 109), "la NGP se construye con referencia a un marco discursivo del orden neoliberal clasico, la PNGP se vincula con un orden discursivo de democracia social". Entretanto, "la PNGP pone el acento en formas colaborativas como mecanismos de resolución de problemas públicos, con base en instrumentos no referenciados en la NGP".

Ainda que exista uma relação de interdependência entre os fundamentos da NGP e a da PNGP, é possível destacar diferenças nas características e abordagens de cada um destes modelos de gestão. Van Gestel e Teelken (2004, p. 437) esclarecem que "la NGP mantiene las ideas de la administración central que consideran como aspectos clave la dirección, la administración y el control". Por sua vez, a PGNP é "[...] una alternativa a la burocracia jerárquica y a la NGP, pero se basa menos en los principios de mercado, como la competencia y la rivalidad, y más en la cooperación entre el gobierno y los actores ajenos al estado".

FIGURA 1 - PRINCIPAIS ENFOQUES DA NGP E DA PNGP
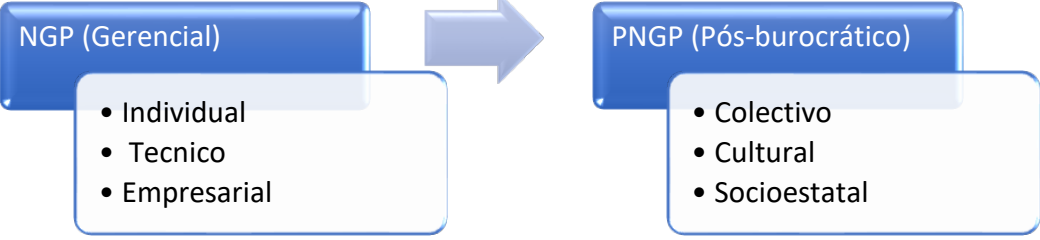

FONTE: Elaborada pelos autores baseado em Vélez e Ortiz (2016). 
Como podemos observar na figura 1, há uma diferença explícita no que se refere à dimensão estrutural que fundamenta as duas vertentes, enfatizando uma abordagem distinta no ethos e na cultura que contextualizam a NGP e a PNGP.

Aprofundando um pouco mais nossa análise, levando em consideração as abordagens de cada uma das correntes que ensejam um novo paradigma político da administração pública, verificamos que o ponto central que delimita as diferenças entre a NGP e a PNGP pode ser a perspectiva da relação entre Estado e mercado. Enquanto a NGP desenvolveu mecanismos gerenciais a partir de uma "matriz mercadocêntrica", associada à gestão empresarial no setor público, a PNGP reformulou a concepção weberiana de "matriz estadocêntrica", baseada na construção de uma agenda pública intervencionista, mais convergente com o modelo de bem-estar social (VÉLEZ; ORTIZ, 2016).

Neste sentido, podemos inferir que a transição da NGP para a PNGP, em certa medida, não apresenta grandes transformações em sua configuração, denotando uma releitura que não rompe com as premissas de sua antecessora. Contudo, as bases teóricas de sustentação seguem sendo divergentes, o que nos leva a pensar que "tal vez post NGP es más que una extensión o una adaptación del concepto de NGP, aunque sus premisas básicas sean similares (VAN GESTEL; TEELKEN, 2004, p. 430). O quadro 1 apresenta uma comparação entre a NGP e a PNGP a partir dos seus principais fundamentos.

\section{QUADRO 1 - PRINCIPAIS CARACTERÍSTICAS DA NGP E DA PNGP}

\begin{tabular}{|l|l|l|}
\hline \multicolumn{1}{|c|}{ Características } & \multicolumn{1}{|c|}{ NGP } & \multicolumn{1}{c|}{ PNGP } \\
\hline Fundamentos normativos & Racionalidade e eficiência & $\begin{array}{l}\text { Equidade social, humanização e } \\
\text { democracia }\end{array}$ \\
\hline Matriz gerencial & Mercadocêntrica & Estadocêntrica \\
\hline Modelo de governança & Empresarial, mercado & Trabalho em rede \\
\hline Políticas públicas & $\begin{array}{l}\text { Fortalecimento do governo } \\
\text { central, controle das decisões }\end{array}$ & $\begin{array}{l}\text { Políticas públicas e administração } \\
\text { conjunta, autodireção }\end{array}$ \\
\hline Metas e estratégias & $\begin{array}{l}\text { Redução de custos e melhoria } \\
\text { da qualidade }\end{array}$ & $\begin{array}{l}\text { Centrado nos problemas da } \\
\text { sociedade, melhoria da confiança } \\
\text { e da criatividade }\end{array}$ \\
\hline
\end{tabular}

FONTE: Elaborado pelos autores baseado em Van Gestel e Teelken (2004).

O quadro 1 destaca diferentes abordagens da NGP e da PNGP a partir das bases que a fundamentam. As características apresentadas reforçam a ideia de que a NGP se desenvolve por meio de ações mais conservadoras, alinhada a uma perspectiva ideológica liberal, enquanto a PNGP se fundamenta em 
bases progressistas, denotando um caráter mais flexível, convergindo para uma estrutura de Estado recentralizada e estimulando o fortalecimento de processos de coordenação vertical e horizontal (VÉLEZ; ORTIZ, 2016).

No que se refere à área educacional, de acordo com Tolofari (2005), a NGP foi um fenômeno global que se espalhou rapidamente em vários países na década de 1980, influenciando de forma significativa as políticas governamentais. Assim como em outros setores da administração pública, a educação também foi impactada pela implementação de políticas gerencialistas relacionadas à NGP, legitimadas a partir das reformas ocorridas no final do século XX.

Seguindo a tendência globalizadora da NGP, vários países da América Latina iniciaram um processo de reforma da administração pública embasados nos pressupostos desta tendência que já se consolidava em várias partes do mundo. As reformas globais baseadas na NGP caracterizam-se por: "[...] la planificación estratégica, la mejora de los sistemas de gestión presupuestaria y financiera, la gestión orientada a resultados, la cualificación del funcionariado" (BROUCHOUD, 2009, p. 129).

Muitos países latino-americanos iniciaram suas reformas influenciadas pela NGP, porém, em alguns contextos, a implementação dessas políticas foi contaminada por "características estructurales e históricas del servicio civil, por los arraigados mecanismos de corrupción que se muestran como una de las mayores limitaciones, junto con las relaciones clientelares que atraviesan la cultura organizacional" (BROUCHOUD, 2009, p. 137).

Mesmo diante das dificuldades de implantação em função das características estruturais e históricas, podemos observar traços marcantes na NGP e da PNGP nestes países, ainda que com fragilidades no que se refere à instabilidade e à falta de coordenação. Esse panorama agrava-se ainda mais por pressões de organismos multilaterais que condicionam seus investimentos, de forma coercitiva, à implementação de medidas em áreas estratégicas, possibilitando maior rentabilidade dos recursos.

No caso do Brasil, um dos únicos países latino-americanos que concluíram a reforma na administração pública na década de 1990, a influência da NGP se torna mais evidente, seja por meio da profissionalização do serviço público ou pela privatização da máquina estatal. "En el caso de Brasil, algunos de sus estados, a fines de los ochenta, implementaron cambios en la planta de funcionarios, por medio de la fijación de incentivos, una contratación más cuidadosa, flexibilidad organizativa y el control de la comunidad" (BROUCHOUD, 2009, p. 129).

Os autores que estudam alguns dos elementos da NGP no Brasil esclarecem que sua influência foi profunda na organização das escolas, nos modelos curriculares e na formação de professores (HYPOLITO, 2011), assim como reestruturou os mecanismos de avaliação (WERLE, 2011) e de financiamento da educação (DAVIES, 2014). 
Nos países da Europa, a NGP fortalece-se com o discurso da promoção de políticas de melhoria da qualidade da educação básica, em consonância com as determinações estabelecidas em conjunto pelos países da União Europeia. Esta postura do bloco europeu estimula a criação de mecanismos de monitoramento do rendimento educacional dos alunos por meio de avaliações padronizadas, a exemplo do PISA $^{5}$, de forma a consolidar uma política de ranqueamento embasada na comparação dos resultados obtidos em cada país.

Em meio a essa conjuntura de racionalidade da educação, a Espanha desenvolve seu sistema educacional alinhado aos marcos regulatórios e programas implementados em outros países da União Europeia. Ainda que as reformas tenham impactado de maneira diferente em cada país de acordo com a sua especificidade e contexto, na Espanha a NGP "ha estimulado el mayor alcance político de la evaluación educativa, y la mayor presencia de planes estratégicos e indicadores de desempeño (VERGER; NORMAN, 2015, p. 603).

Fundamentados nas mesmas concepções, a PNGP, mesmo seguindo um caminho divergente, busca resultados semelhantes. Enquanto "la NGP se basa en la diferenciación entre política y administración, y en el marco de las políticas públicas [...]", "la PNGP se basa en mecanismos cooperativos entre los procesos políticos y los procesos de gestión" (VÉLEZ; ORTIZ, 2016, p. 110).

Após essa breve contextualização, cabe destacar que nosso objetivo não é de questionar se a PNGP é uma ruptura ou uma continuidade da NGP, mas sim de sistematizar o percurso estabelecido por essas duas vertentes, enfatizando suas principais características, de forma a definir parâmetros que nos auxiliem a compreender em que bases estão firmadas a administração pública e a gestão da educação no Brasil e na Espanha, objeto de estudo desta pesquisa.

\section{Estudo comparado dos sistemas educacionais brasileiro e espanhol: principais aspectos}

Nossa investigação utilizou o método comparado com o objetivo de identificar critérios que norteiam as diretrizes dos sistemas educacionais no Brasil e na Espanha. A comparação permite-nos fazer uma análise estrutural, verificando as diferenças e semelhanças que distinguem os dois países, a partir dos fundamentos da NGP e da PNGP.

5 Programa Internacional de Avaliação de Alunos promovido pela Organização para a Cooperação e Desenvolvimento Econômico (OCDE). 
Ademais, muitos pesquisadores têm seguido essa estratégia metodológica (COWEN, 2018; ESPEJO VILLAR; CALVO ÁLVAREZ, 2018; MATARRANZ, 2019), consolidando uma tendência cada vez mais recorrente que consiste em desenvolver estudos comparados de sistemas educativos, servindo de parâmetros para organismos internacionais e instituições públicas que realizam ações simultâneas, facilitando a sistematização de dados e a implementação de políticas públicas conjuntas (GARRIDO, 1997).

A comparação entre Brasil e Espanha justifica-se, em primeiro lugar, porque os dois países têm uma configuração político-administrativa relativamente semelhante, baseada na descentralização da educação com uma relação de dependência do governo central. Esse formato estimula a autonomia das instituições públicas que fazem parte do sistema.

Outra característica comum é que os dois países implementaram reformas gerais na administração pública e no âmbito da educação na década de 1990 , em busca do fortalecimento do processo democrático, rompendo com os modelos conservadores dos governos anteriores. A busca pela modernização da administração pública, nos dois casos, sofreu a influência da globalização e das tendências gerencialistas que ecoavam em todo o mundo ao final do século XX.

A partir do referencial teórico que embasa a presente pesquisa foi possível identificar as principais características da NGP e da PNGP no âmbito dos sistemas educacionais de Brasil e Espanha. Neste sentido, sistematizamos os dados por meio das seguintes categorias de análise: descentralização, relações públicoprivadas e avaliação (Quadro 2).

QUADRO 2 - PRINCIPAIS CARACTERÍSTICAS DA NGP E DA PNGP NO BRASIL E NA ESPANHA A PARTIR DAS CATEGORIAS DE ANÁLISE

\begin{tabular}{|c|c|c|}
\hline Categorias de análise & NGP & PNGP \\
\hline Descentralização & $\begin{array}{l}\text { - Poder concentrado nos órgãos } \\
\text { centrais (Estado regulador); } \\
\text { - Responsabilização da gestão } \\
\text { local e das escolas; } \\
\text { - Escolas atuando como executores } \\
\text { de procedimentos administrativos. }\end{array}$ & $\begin{array}{l}\text { - Autonomia dos governos locais } \\
\text { e das escolas; } \\
\text { - Políticas públicas e administração } \\
\text { conjunta; } \\
\text { - Distribuição de recursos com } \\
\text { ênfase na prestação de contas. }\end{array}$ \\
\hline $\begin{array}{l}\text { Relações } \\
\text { público-privadas }\end{array}$ & $\begin{array}{l}\text { - Recursos públicos investidos em } \\
\text { instituições privadas; } \\
\text {-Ampliação da oferta de instituições } \\
\text { educacionais privadas (concertadas } \\
\text { na Espanha e ensino superior no } \\
\text { Brasil); } \\
\text { - Profissionalização do diretor } \\
\text { escolar. }\end{array}$ & $\begin{array}{l}\text { - Privatização da gestão das } \\
\text { escolas; } \\
\text { - Participação da comunidade } \\
\text { na resolução dos problemas das } \\
\text { escolas; } \\
\text { - Padronização dos currículos e } \\
\text { conteúdos trabalhados nas escolas } \\
\text { (apostilamento). }\end{array}$ \\
\hline
\end{tabular}

Continua 
Conclusão

\begin{tabular}{|l|l|l|}
\hline Categorias de análise & \multicolumn{1}{|c|}{ NGP } & \multicolumn{1}{c|}{ PNGP } \\
\hline Avaliação & - Ranqueamento das escolas; & - Marketing educacional; \\
& - Competição entre escolas e & - Criação de agências de avaliação \\
& países; & com foco no resultado; \\
& - Ênfase nos dados estatísticos; & - Rendimento escolar associado à \\
& - Avaliações padronizadas. & qualidade educativa. \\
\hline
\end{tabular}

FONTE: Elaborado pelos autores

Como podemos verificar no quadro 2 , a descentralização foi uma estratégia utilizada tanto na NGP como na PNGP, como uma forma de efetivação de um modelo de governança. Entretanto, na NGP o intuito era de descentralizar apenas a execução das determinações do governo central (Estado regulador), permanecendo centralizado o planejamento, a avaliação e os recursos financeiros. Já a PNGP utiliza a descentralização como forma de responsabilização, fortalecendo o mecanismo de prestação de contas.

No que se refere às parcerias público-privadas, o enfoque também é divergente nas duas vertentes. Na NGP, a ênfase foi nas privatizações e investimentos de recursos financeiros públicos em instituições privadas. $\mathrm{Na}$ PNGP, a ênfase foi em parcerias, em regime de colaboração e trabalhos em rede.

Com relação à avaliação, houve certa continuidade, ampliando as estratégias de avaliações em larga escala da NGP, estendendo e valorizando ainda mais no período da PNGP, além de multiplicar a quantidade de avaliações e a preocupação em atingir os índices estatísticos estabelecidos pelos organismos internacionais, ou seja, associando-os à qualidade da educação.

A seguir aprofundaremos as categorias de análise apresentando mais dados relativos à transição da NGP para a PNGP no Brasil e na Espanha.

\section{Descentralização}

Para que as reformas na administração pública atingissem seus objetivos era imprescindível criar mecanismos de descentralização ou desconcentração, criando uma estrutura de governança capaz de absorver as determinações estabelecidas pelo governo central. Ainda que a descentralização seja preliminarmente uma ferramenta relacionada à autonomia, numa perspectiva mais generalista, paradoxalmente, utiliza-se essa ferramenta como uma estratégia gerencial de reforço de centralidade e manutenção de poder. 
Entretanto, a descentralização tem um caráter político e técnico que depende de uma série de variáveis, desde a configuração territorial, até a participação dos atores e da comunidade em geral. O Brasil tem uma organização política e administrativa federalista, ou seja, um modelo de descentralização federal (PUELLES, 1993). Tradicionalmente, a Espanha é um país fortemente centralizado e que atualmente utiliza um modelo de gestão educacional de descentralização intermediária. Em muitos países impera um regime de centralização, (PUELLES, 1993), mas em vários deles as formas de organização vêm se modificando em função de diversos aspectos, ou seja, a centralização e a descentralização não são situações estáticas.

No caso do Brasil, estados e municípios têm um alto grau de autonomia (BRASIL, 1996a), apesar de dependerem muito dos recursos financeiros do governo federal. No caso específico dos municípios, a situação é mais grave. Estudos mostram que mais da metade das matrículas no ensino fundamental são de responsabilidade dos municípios, entes federativos com menor capacidade de arrecadação (PINTO, 2014). Enquanto isso, o que tem ocorrido nas últimas décadas na Espanha é um fortalecimento das autoridades locais e instituições escolares, inclusive através da transferência de recursos financeiros.

No que se refere à autonomia na gestão da educação, alguns autores advertem que ela tem sido utilizada como "régimen de regulación postburocrática", muito frequente nos países da Europa na década de 1990, no contexto da governança em condições de "cuasi-mercado". Para Bolívar (2009, p. 37), "una mayor descentralización y refuerzo de autonomía de la escuela, se no si inserta en un marco de defesa de la escuela pública, puede dar lugar a la fragmentación o polarización (pública/privada) del servicio educativo”. Ou seja, a autonomia em seu sentido mais amplo de articulação e fortalecimento das comunidades locais não é concebida para legitimar o poder de decisão dos atores envolvidos na educação, podendo tornar-se um mecanismo mais centralizador ainda.

Há, pois, um conflito que se estabelece na gestão educacional e que contribui para a efetivação do modelo gerencialista, constituindo-se em um paradoxo do Estado moderno: adotar estratégias centralizadoras para a manutenção e a regulação do poder, implementando medidas descentralizadoras de responsabilização das instituições locais, incorrendo no risco de perder o controle efetivo. O ponto central da discussão é o grau de tomada de decisão que tem sido levado às instituições escolares para que se mantenha uma qualidade de ensino, respeitando as especificidades de cada região, potencializando as condições de estabelecer suas próprias diretrizes, com base nas diretrizes gerais. 
Porém, é importante destacar que "la autonomía, pues, está siendo utilizada como un nuevo gerencialismo en educación” (BOLÍVAR, 2009, p. 60).

No Brasil, o discurso da autonomia que se estabelece na legislação nem sempre é consolidado na prática. Embora muito debatido, o tema acaba concentrando-se em transferências de recursos ou eleições para diretores (SOUZA, 2009). Na Espanha, a autonomia efetiva-se segundo a tradição gerencialista, porém caracterizada pelo excesso de normativismo "incrustada en la cultura organizativa de la Administración", em um contexto em que "la autonomía escolar se juega en el segundo" (BOLÍVAR, 2009, p. 52).

Se por um lado a gestão (central ou local) não cria condições de autonomia nas escolas, por outro lado, as próprias escolas não estão interessadas em fazêlo e, claro, este processo não ocorre sozinho. "No basta decretarla, pues no preexiste a la acción de los sujetos, sino que es asunto de crear las condiciones para que cada escuela pueda, en un largo proceso, construir organizativamente su autonomía" (BOLÍVAR, 2009, p. 39).

Neste contexto tão complexo de implementação da descentralização no âmbito dos sistemas educacionais, destacamos a influência da legislação nos dois países. No Brasil, tanto a NGP como a PNGP se legitimam por meio da Lei de Diretrizes e Bases da Educação Nacional (BRASIL, 1996a). Os artigos 10 e 11, que estabelecem as atribuições de estados e municípios, responsabilizam os entes federados pela oferta de toda a Educação Básica. Cabe destacar que a legislação reforça tanto a ideia de responsabilização dos estados e municípios (NGP), como a de estímulo à administração conjunta em regime de colaboração (PNGP).

$\mathrm{Na}$ Espanha, no período da NGP foi implementada a Ley Orgánica de Ordenación General del Sistema Educativo ${ }^{6}$ (ESPAÑA, 1990). A referida lei é considerada uma das mais importantes da educação espanhola, propondo tanto a nível estrutural como de desenvolvimento organizacional uma série de mudanças, incorporando o discurso da qualidade educativa e autonomia das escolas, ainda que a Ley Orgánica de Participación, Evaluación y Gobierno de los centros docentes ${ }^{7}$ (ESPAÑA, 1995) estabeleça o discurso tecnocrático, que consolida as leis conservadoras. Mais alinhado ao período da PNGP, foi aprovada a Ley Orgánica de la Mejora de la Calidad Educativa ${ }^{8}$ (ESPAÑA, 2013), que reforça o discurso de modernização da administração pública, fundamentado no liberalismo econômico e no capitalismo moderno.

6 Ley Orgánica de Ordenación General del Sistema Educativo (LOGSE).

7 Ley Orgánica de Participación, Evaluación y Gobierno de los Centros Docentes (LOPEGSE). 8 Ley Orgánica de la Mejora de la Calidad Educativa (LOMCE). 


\section{Relações público-privadas}

Uma das estratégias mais utilizadas por quase todos os países do mundo que promoveram transformações na administração pública por meio das reformas é o estreitamento das relações público-privadas, como uma forma de combater a crise econômica mundial que começou a impactar nas políticas de bem-estar social, principalmente nos países da Europa (BALL, 2014).

Considerado por muitos como um mecanismo neoliberal de saneamento das contas públicas, reproduzindo a ideologia liberal do Estado mínimo (BALL, 2014; HOOD, 2000), o fato é que cada vez mais países estão terceirizando os serviços educativos como uma nova oportunidade de investimento internacional (BALL, 2014).

De acordo com Ball (2014), a privatização da educação e das políticas públicas como um fenômeno internacional é uma tendência que vem se intensificando, financiada por organismos internacionais (Banco Mundial), fortalecendo o que ele chama de "indústria dos serviços educativos". Para o autor, os mercados educativos que vem se desenvolvendo amplamente "trascienden la división educación pública/educación privada, y transforman todos los servicios de la educación en mercancías que pueden comercializarse y de las cuales pueden extraerse ganancias" (BALL, 2014, p. 3). O comércio de serviços educacionais é amplo e diverso, atendendo a todos os tipos de demanda, desde a gestão das escolas, consultorias especializadas, organização curricular, desenvolvimento de programas, implantação de novas tecnologias, capacitação e formação de professores, etc.

$\mathrm{Na}$ comparação da NGP com a PNGP no que se refere às parcerias público-privadas, observa-se uma abordagem diferenciada. Na NGP, as ações estavam centradas na transferência de recursos ou de alunos à iniciativa privada, reforçando o discurso da diminuição do papel do Estado na oferta educativa. Já na PNGP, a principal estratégia foi a de buscar parcerias em instituições privadas, trazendo-as para o sistema educacional público. Tanto no Brasil (DOURADO, 2002) como na Espanha (VERGER; CURRAN; PARCERISA, 2015), o estreitamento das relações público-privadas produziu um aumento dos investimentos públicos em instituições privadas, alterando de forma significativa a configuração dos sistemas educacionais, incorporando estratégias gerenciais que fortalecem uma concepção racionalista de educação.

No Brasil, a relação entre o público e o privado na política educacional é parte das mudanças sociais e econômicas que ocorreram no contexto das transformações do papel do Estado. O processo de privatização da educação 
brasileira se dá por meio da gestão das escolas, da execução de políticas educacionais e da agenda educacional, que está alinhada à lógica do mercado (PERONI; CAETANO, 2015). A título de ilustração, recentemente, os estados de Mato Grosso e de Goiás implementaram políticas de privatização da gestão de escolas que fazem parte do seu sistema educacional (MATO GROSSO, 2011; GOIÁS, 2013).

No caso da Espanha, uma das formas mais evidentes foi o uso de fórmulas como a de repasse de recursos públicos a escolas privadas (denominados a partir da Ley Orgánica Reguladora del Derecho a la Educación como centros

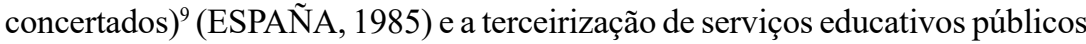
para empresas privadas. Verger, Curran y Parcerisa esclarecem que "esta alianza público-privada que rige el sistema educativo español desde mediados de los ochenta permitió, en sus comienzos, lograr una rápida evolución educativa a bajo coste" (VERGER; CURRAN; PARCERISA, 2015, p. 680).

$\mathrm{O}$ que era para ser uma medida emergencial, visando minimizar os efeitos de uma crise econômica que agravou a situação educacional na Espanha na década de 1980, acabou se transformando em regra. Atualmente, do total de instituições de matrículas não universitárias na Espanha, 32,8\% são centros privados, sendo que a sua grande maioria são escolas concertadas (ESPAÑA, 2019).

Com relação à legislação educacional no Brasil, há evidências de um estímulo cada vez maior das relações público-privadas como uma forma de minimizar o impacto econômico com os custos de manutenção do sistema educacional público. A título de exemplo, a Resolução $n^{0} 1$, de 2012, dispõe sobre a implementação do regime de colaboração mediante Arranjo de Desenvolvimento da Educação (ADE), como instrumento de gestão pública para a melhoria da qualidade social da educação. A resolução legitima a parceria em regime de colaboração, como um instrumento de gestão educacional entre instituições públicas e privadas, conforme estabelece o parágrafo 1 do artigo 2 (BRASIL, 2012). Entretanto, a parceria público-privado no âmbito da administração pública brasileira já vem sendo estimulada por meio da legislação federal há muito tempo (BRASIL, 2004).

Com relação à legislação educacional na Espanha, o que se verifica é que a implementação de políticas públicas embasadas na aproximação com instituições privadas no sistema educacional público espanhol estimulou a competitividade dos centros escolares, gerando uma disputa entre alunos e escolas em busca da "qualidade" que ocupa um lugar destacado no "marketing 
educacional". A Ley Orgánica de la Mejora de la Calidad Educativa (ESPAÑA, 2013), alinhada aos pressupostos da NGP, está centrada na padronização dos processos formativos, com vistas a atingir os níveis educacionais estabelecidos pelos organismos internacionais.

Nessa mesma base de fundamentos, a PNGP busca fortalecer a profissionalização no âmbito escolar (diretor, professores), utilizando como mecanismo a simplificação dos currículos e a instrumentalização dos conhecimentos, além de estabelecer novos coletivos que são enaltecidos na "marquetização" da aprendizagem.

Nesse sentido, fica evidente que as políticas de ampliação das relações público-privadas no âmbito dos sistemas educacionais, tanto no Brasil como na Espanha, se intensificaram a partir das reformas dos anos de 1990. Mais do que uma tendência, a consolidação da aproximação público-privada no contexto da gestão educacional institucionalizou uma concepção de educação que privilegia as leis de mercado como uma diretriz globalizadora em nossa sociedade atual.

\section{Avaliação}

A avaliação educacional tornou-se um dos principais mecanismos de regulação, associada à comparação e ao ranqueamento do ensino. As consequências diretas dessa ação são o incentivo à competição entre escolas e estudantes, a segregação acadêmica e a busca excessiva de resultados, frequentemente associados à qualidade da educação.

Nesse sentido, a avaliação padronizada é reforçada como um índice estatístico para medir a "qualidade" da educação, a fim de conquistar clientes (leis de mercado), mantendo a satisfação com os serviços prestados (BOLÍVAR, 2009). Assim, constituímos um sistema educacional contaminado com a lógica do mercado, que busca incessantemente a produtividade e a melhoria constante dos resultados, através da responsabilidade das instituições escolares pelo sucesso ou fracasso do ensino.

Para Verger e Normand (2015, p. 603), "La NGP ha estimulado el mayor alcance político de la evaluación educativa, y la mayor presencia de planes estratégicos e indicadores de desempeño en base a los que asignar recursos a los centros". Em outras palavras, a avaliação educacional tem sido usada como um mecanismo de monitoramento do rendimento escolar, de forma que as políticas educacionais implementadas no âmbito da NGP condicionam o repasse de recursos somente para as escolas que apresentem bons resultados. 
Diante desse panorama de cobrança por resultados, a pressão por conseguir alcançar o rendimento padrão desejado pelos órgãos gestores é muito grande, transformando um dado estatístico no principal objetivo da escola. Dessa forma, a avaliação deixa de ser um instrumento diagnóstico para se transformar num mecanismo de "validação" para justificar o investimento financeiro na escola. Velez e Ortiz (2016) esclarecem que na PNGP a avaliação continua tendo muita centralidade, fortalecendo cada vez mais políticas de remuneração baseadas no desempenho.

No Brasil, as iniciativas de políticas de avaliação em larga escala intensificaram-se no final da década de 1980, com a criação do Sistema Nacional de Avaliação da Educação Pública - SAEP (WERLE, 2011). Nas próximas décadas, a avaliação em larga escala foi fortalecida e diversificada, mas cumprindo sempre seu papel de introduzir uma ideia de "medição da qualidade" da educação, em consonância com as políticas de comparação com outros países, "para responder as estratégias gerencialistas de modernização e racionalização voltadas para resultados" (WERLE, 2011, p. 790). Além disso, é preciso destacar que a padronização dos processos de avaliação "retira a escola de um patamar de autoidentidade formulada a partir de seu próprio olhar para lançá-la como organização caracterizada por uma linguagem padrão universalizante e unificadora" (WERLE, 2011, p. 790).

Também por volta dos anos de 1980, a Espanha começou a planejar processos de avaliação das escolas, englobando "la evaluación del currículo, de los programas de enseñanza o del rendimiento de los estudiantes" (TIANA-FERRER, 2018, p. 19). A consolidação de avaliações padronizadas em nível nacional sustentou-se no argumento da busca pela qualidade educacional. Com o passar do tempo, a avaliação externa, na Espanha, tornou-se uma forte aliada das políticas gerencialistas, legitimadas pela legislação espanhola (ESPAÑA, 1990), alinhadas aos padrões de classificação e competitividade internacional, a exemplo do PISA.

A legislação no Brasil vem dando ênfase ao sistema de avaliação educacional, tanto na NGP quanto na PNGP. Em 1996, foi aprovada a Emenda Constitucional n. 14, que criou o Fundo de Manutenção e Desenvolvimento do Ensino Fundamental e de Valorização do Magistério (Fundef) e que estabeleceu um valor por aluno que corresponde a um padrão mínimo de qualidade de ensino (BRASIL, 1996b) ${ }^{10}$. O Plano Nacional de Educação (BRASIL, 2014) também enfatiza a importância dos sistemas de avaliação em todos os níveis de ensino, propondo a implantação de sistemas de informação capazes de coletar dados sobre o rendimento escolar dos alunos.

10 Em 2006, o Fundef foi substituído pelo Fundo de Manutenção e Desenvolvimento da Educação Básica e de Valorização dos Profissionais da Educação (Fundeb), ampliando a abrangência do fundo para a Educação Básica. 
No que se refere à legislação educacional na Espanha, alinhada à NGP, em 1995 foi aprovada a Ley Orgánica de la Participación, la Evaluación y el Gobierno de los Centros Docentes (ESPAÑA, 1995), com foco no rendimento escolar e na qualidade educativa entendido em termos de produto. A lei também inclui o papel do diretor da escola, como gerente tecnocrático do centro educacional, desenvolvendo a exigência de um perfil qualificado para esse cargo de gestão e reforçando a dimensão avaliativa de natureza institucional que havia sido criada anteriormente na LOGSE com a criação de agências de avaliação (Instituto Nacional de Qualidade e Avaliação) com o objetivo de organizar a avaliação do sistema educacional espanhol e coordenar as avaliações realizadas por organizações internacionais.

No âmbito do PNGP, a Ley Orgánica de Calidad Educativa" ${ }^{11}$ (ESPAÑA, 2002) e a Ley Orgánica de la Mejora de la Calidad de la Educación (ESPAÑA, 2013) representam a linha discursiva de formalização de um modelo de qualidade entendido em termos de desempenho e quantificação da educação.

Diante do exposto podemos verificar a intencionalidade das políticas de avaliação, tanto no Brasil como na Espanha, alinhadas às lógicas de mercado, legitimando as autoridades reguladoras locais (estados e municípios no caso brasileiro e Comunidades Autônomas no caso espanhol) como órgãos executores de processos padronizados de ensino, em consonância com as tendências da NGP e da PNGP.

\section{Considerações finais}

A presente pesquisa buscou investigar os principais aspectos relacionados à expansão da NGP e, posteriormente, da PNGP no âmbito dos sistemas educacionais do Brasil e da Espanha. Nossa análise centrou-se nas três dimensões em que esses modelos de gestão se desenvolvem com mais ênfase e que, em nosso artigo, estabelecemos como categorias de análise: descentralização, relações público-privadas e avaliação.

Nossa intenção foi a de sistematizar a transição da NGP para a PNGP, dando ênfase à dimensão educacional, identificando as transformações ocorridas por esta mudança na administração pública e na gestão da educação, apontando possíveis fragilidades nestes modelos de gestão e suas influências na educação. 
Com relação à metodologia utilizada na pesquisa, comparando os efeitos causados pela NGP e PNGP nos sistemas educacionais do Brasil e da Espanha, podemos concluir que a partir de uma perspectiva do "institucionalismo mundial", fortalecendo a ideia da construção de um modelo padronizado de educação, existem muitas semelhanças entre a educação pública brasileira e a espanhola.

Dadas as especificidades de cada país, com suas estruturas e características peculiares, a adoção de políticas públicas (verificada nos dois países) baseadas na NGP e na PNGP reforça o discurso de racionalidade educacional, alinhado à lógica de um Estado supranacional, regulador do sistema educacional e das escolas a ele pertencentes.

Fundamentados nos aspectos estruturais da PNGP, modelo de gestão educacional utilizado por muitos países na atualidade, podemos esperar para os próximos anos uma maior flexibilidade nas ações governamentais com relação à NGP, ampliando a esfera "colaborativa" da sociedade civil, porém sem grandes alterações relativas às diretrizes estabelecidas para curto e médio prazos, legitimando uma tendência globalizadora de educação mundial padronizada.

\section{REFERÊNCIAS}

BALL, Stephen. Globalización, mercantilización y privatización: tendencias internacionales en Educación y Política Educativa. Archivos Analíticos de Políticas, [s.l.], v. 22, n. 41, p. 1-17, jun. 2014.

BOLÍVAR, Antonio. La autonomía en la gestión como nuevo modo de regulación. Espacios en Blanco. Revista de Educación, Buenos Aires, v. 19, p. 35-68, jun. 2009.

BRASIL. Lei $n^{\circ}$ 9394, de 20 de dezembro de 1996. Estabelece as diretrizes e bases da educação nacional. Brasília, DF: Presidência da República, 1996a. Disponível em: http:// www.planalto.gov.br/ccivil_03/leis/19394.htm. Acesso em: 12 maio 2019.

BRASIL. Lei n ${ }^{\circ}$ 9.424, de 24 de dezembro de 1996. Dispõe sobre o Fundo de Manutenção e Desenvolvimento do Ensino Fundamental e de Valorização do Magistério. Brasília, DF: Presidência da República, 1996b. Disponível em: http://www.planalto.gov.br/ccivil_03/ LEIS/L9424.htm. Acesso em: 10 abr. 2020.

BRASIL. Lei $n^{\circ} 11.079$, de 30 de dezembro de 2004. Dispõe sobre a contratação de parcerias público-privada, instituindo normas para a concessão de serviços públicos e obras públicas. Brasília, DF: Presidência da República, 2004. Disponível em: http:// www.planalto.gov.br/ccivil_03/_Ato2004-2006/2004/Lei/L11079.htm. Acesso em: 18 abr. 2020. 
BRASIL. Ministério da Educação. Resolução n. 1 de 23 de janeiro de 2012. Conselho Nacional de Educação. Dispõe sobre a implementação do regime de colaboração mediante Arranjo de Desenvolvimento da Educação. Brasília, DF: Ministério da Educação, 2012. Disponível em: http://portal.mec.gov.br/index.php?option=com docman\&view $=$ download\&alias=9816-rceb001-12\&Itemid=30192. Acesso em: 13 abr. 2020 .

BRASIL. Lei $n^{\circ}$ 13.005, de 25 de junho de 2014. Aprova o Plano Nacional de Educação e dá outras providências. Brasília, DF: Presidência da República, 2014b. Disponível em: https://www.planalto.gov.br/ccivil_03/_ato2011-2014/2014/lei/113005.htm. Acesso em: 20 maio 2019.

BROUCHOUD, María F. R. Las reformas del Estado y la administración pública en América Latina y los intentos de aplicación del New Public Management. Estudios Políticos, Medellín, n. 34, p. 115-141, ene./jun. 2009.

COHEN, Benjamin J. International political economy. An intellectual history. Princeton/ Oxford: Princeton University Press, 2008.

COWEN, Robert. Re-thinking comparative education and religion: temptations, traditions, and politics. Revista Española de Educación Comparada, Madrid, n. 33, p. 28-45, 2019.

DALE, Roger. Globalização e educação: demonstrando a existência de uma cultura educacional comum ou localizando uma agenda globalmente estruturada para a educação. Educação \& Sociedade, Campinas, v. 25, n. 87, p. 423-460, maio/ago. 2004.

DAVIES, Nicholas. Alguns desafios do financiamento da educação. Revista Pedagógica, Chapecó, v. 17, n. 33, p. 251-267, jul./dez. 2014.

DOURADO, Luiz F. Reforma do estado e as políticas para a educação superior no Brasil nos anos 90. Educação \& Sociedade, Campinas, v. 23, n. 80, p. 234-252, set. 2002.

ESPAÑA. Ley Orgánica 8/1985 de 3 de julio, del Derecho a la Educación. Boletín Oficial del Estado, num. 159, de 4 de julio, 1985.

ESPAÑA. Ley Orgánica 1/1990, de 3 de octubre, de Ordenación General del Sistema Educativo. Boletín Oficial del Estado, de 4 de octubre, 1990.

ESPAÑA. Ley Orgánica 9/1995, de 20 de noviembre, de la Participación, la Evaluación y el Gobierno de los Centros Docentes. Boletín Oficial del Estado, num. 278, 1995.

ESPAÑA. Ley Orgánica 10/2002, de 23 de diciembre, de la Calidad de la Educación. Boletín Oficial del Estado, num. 307, 2002.

ESPAÑA. Ley Orgánica 8/2013, de 9 de diciembre, para la Mejora de la Calidad Educativa. Boletín Oficial del Estado, num. 295, de 10 de diciembre, 2013.

ESPAÑA. Ministerio de Educación y Formación Profesional. Catálogo general de publicaciones oficiales: datos y cifras, curso escolar 2018-2019. Madrid: Ministerio de Educación y Formación Profesional, 2019. 
ESPEJO VILLAR, L. Belén; CALVO ÁLVAREZ, Mª Isabel. Entre las transferencias económicas y la privatización: tendencias de las políticas de inclusión educativa en Argentina y Uruguay. In: CONGRESSO NACIONAL DE EDUCACIÓN COMPARADA, 16., 2018, Tenerife, San Cristóbal de La Laguna, España. Actas [...]. San Cristóbal de La Laguna: Servicio de Publicaciones, Universidad de La Laguna, 2018, p. 499-506. Disponível em: https://educomp.webs.ull.es/wp-content/uploads/2018/10/Actas-XVI-CongresoNacional-Educacio\%CC\%81n-Comparada-Tenerife.pdf. Acesso em: 20 abr. 2020.

GARRIDO, José Luis G. La educación comparada en una sociedad global. Revista Española de Educación Comparada, Madrid, v. 3, p. 61-81, 1997.

GOIÁS. Lei $\mathrm{n}^{\circ} 18.331$, de 30 de dezembro de 2013. Altera a Lei ${ }^{\circ} 15.503$, de 28 de dezembro de 2005 , que dispõe sobre a qualificação de entidades como organizações sociais estaduais. Diário Oficial [do] Estado de Goiás, Goiânia, 31 dez. 2013. Disponível em: http://www.gabinetecivil.goias.gov.br/leis_ordinarias/2013/lei_18331.htm. Acesso em: 29 abr. 2020.

GYÖRGY, Hajnal; ROSTA, Miklos. NPM and post-NPM in the view of European administrative elites: Towards understanding the relationship of public management reform doctrines. In: THE INTERNATIONAL RESEARCH SOCIETY FOR PUBLIC MANAGEMENTE ANNUAL CONFERENCE, XIX, 2015, Birmingham, United Kingdom, p. 1-24. Disponível em : https://www.academia.edu/14106950/NPM_and_postNPM_in_the_view_of_European_administrative_elites_Towards_understanding_the relationship_of_public_management_reform_doctrines. Acesso em: 08 out. 2019.

HOOD, Christopher. Paradoxes of public-sector managerialism, old public management and public service bargains. International Public Management Journal, London, v. 3, p. 1-22, 2000.

HYPOLITO, Álvaro Moreira. Reorganização Gerencialista da Escola e Trabalho Docente. Revista Educação: teoria e prática, Rio Claro, SP, v. 21, p. 1-18, out./dez. 2011.

LINGARD, Bob; RAWOLLE, Shaun. La globalización y el reajuste de las políticas y la política educativa: Implicaciones para la educación comparada. En: LARSEN, Marianne (ed.). Pensamiento innovador en Educación Comparada. Homenaje a Robert Cowen. Madrid: Uned, 2014.

MAROY, Christian; VOISIN, Annelise. As transformações recentes das políticas de accountability na educação: desafios e incidências das ferramentas de ação pública. Educação \& Sociedade, Campinas, v. 34, n. 124, p. 881-901, 2013.

MATARRANZ, María. Propuesta metodológica para estudiar la política educativa supranacional: alumbrando el marco axiológico de la Unión Européa. Revista Española de Educación Comparada, Madrid, n. 34, p. 73-96, jul./dic. 2019.

MATO GROSSO. Lei $n^{\circ}$ 9.641, de 17 de novembro de 2011. Dispõe sobre o Programa Estadual de Parcerias Público-Privadas do Estado de Mato Grosso. Cuiabá: Assembleia Legislativa do Estado. Disponível em: https://www.legisweb.com.br/ legislacao/?id=262609. Acesso em: 29 abr. 2020. 
MOLLER, Jorunn; SKEDSMO, Guri. Nova Gestão Pública na Noruega: o papel do contexto nacional na mediação da reforma educacional. Educação \& Sociedade, Campinas, v. 36, n. 132, p. 779-800, jul./set. 2015.

OLIVEIRA, Dalila A. Nova Gestão Pública e governos democrático-populares: contradições entre a busca da eficiência e a ampliação do direito à educação. Educação \& Sociedade, Campinas, v. 36, n. 132, p. 625-646, jul./set. 2015.

OSBORNE, Stephen. The New Public Governance? Public Management Review, Londres, v. 8, n. 3, 2006.

PINTO, José Marcelino R. Federalismo, descentralização e planejamento da educação: desafios aos municípios. Caderno de Pesquisa, São Paulo, v. 44, n. 153, jul./set. 2014.

PEGORARO, Lucio. Derecho constitucional comparado y uso connotativo de la palabra «derechos» (y de los adjetivos que la acompañan). Anuario Iberoamericano de Justicia Constitucional, Madrid, v. 14, p. 347-372, 2010.

PERONI, Vera Maria V.; CAETANO, Maria Raquel. O público e o privado na educação: projetos em disputa? Revista Retratos da Escola, Brasília, v. 9, n. 17, p. 337-352, jul./dez. 2015.

PUELLES, Manuel. Estudio teórico sobre las experiencias de descentralización educativa. Revista Iberoamericana de Educación, Madrid, n. 3, p. 13-40, 1993.

PUELLES, Manuel. Globalización, neoliberalismo y educación. Revista de la Asociación de Inspectores de Educación de España, Granada, n. 11, p. 1-12, nov. 2009.

SOUZA, Ângelo Ricardo. Explorando e construindo um conceito de gestão escolar democrática. Educação em Revista, Belo Horizonte, v. 25, n. 3, p. 123-140, dez. 2009.

SUBIRATS, J. El análisis de las políticas públicas. Gaceta Sanitária, [s.l.], v. 15, n. 3, p. 259-264, 2001.

STEINER-KHAMSI, Gita. Standards are good (for) businessstandardised comparison and the private sector in education. Globalisation, Societies and Education, Pittsburgh, PA, v. 14, n. 2, p. 161-182, 2016.

TIANA FERRER, Alejandro. Treinta años de evaluación de centros educativos en España. Educación XXI, Madrid, v. 21, n. 2, p. 17-36, 2018.

TOLOFARI, Sowaribi. New public management and education. Policy Futures in Education, Auckland, New Zealand, v. 3, n. 1, p. 75-89, 2005.

VERGER, Antoni; CURRAN, Marta; PARCERISA, Lluís. La trayectoria de una reforma educativa global: el caso de la nueva gestión pública en el sistema educativo catalán. Educação \& Sociedade, Campinas, v. 36, n. 132, p. 675-697, jul./set. 2015.

VERGER, Antoni; NORMAND, Romuald. Nueva gestión pública y educación: elementos teóricos y conceptuales para el estudio de un modelo de reforma educativa global. Educação \& Sociedade, Campinas, v. 36, n. 132, p. 599-622, jul./set. 2015. 
WERLE, Flavia O. C. Políticas de avaliação em larga escala na educação básica: do controle de resultados à intervenção nos processos de operacionalização do ensino. Ensaio: Avaliação e políticas públicas em educação, Rio de Janeiro, v. 19, n. 73, p. 769-792, out./dez. 2011.

VAN GESTEL, Nicolette; TEELKEN, Christine. Servicios de educación superior y de seguridad social en los Países Bajos: institucionalismo y nueva gestión política. Gestión y Política Pública, [s.l.], v. 13, n. 2, p. 427-467, 2004.

VÉLEZ, Sergio Alberto C.; ORTIZ, Cristian Andrés S. Nueva y posnueva gestión pública ¿Continuidad o ruptura de las doctrinas de reforma a partir de 1990? Administración \& Desarrollo, Bogotá, v. 46, n. 1, p. 100-125, 2016.

Texto recebido em 28/05/2019.

Texto aprovado em 06/05/2020. 